\title{
Correlation between Physical Activity and Lung Function in Dusty Areas: Results from the Chronic Obstructive Pulmonary Disease in Dusty Areas (CODA) Cohort
}

\author{
Yuri Han, M.S. ${ }^{1}{ }^{(\mathbb{D}}$, Yeonjeong Heo, M.D. ${ }^{1}$, Yoonki Hong, M.D. ${ }^{1}$, Sung Ok Kwon, Ph.D. ${ }^{2}$ \\ and Woo Jin Kim, M.D. ${ }^{1}$ (i) \\ ${ }^{1}$ Department of Internal Medicine and Environmental Health Center, Kangwon National University, Chuncheon, ${ }^{2}$ Biomedical \\ Research Institute, Kangwon National University Hospital, Chuncheon, Korea
}

Background: Although physical activity is known to be beneficial to lung function, few studies have been conducted to investigate the correlation between physical activity and lung function in dusty areas. Therefore, the purpose of this study is to investigate the correlation between physical activity and lung function in a Korean cohort including normal and COPD-diagnosed participants.

Methods: Data obtained from the COPD in dusty areas (CODA) cohort was analyzed for the following factors: lung function, symptoms, and information about physical activity. Information on physical activity was valuated using questionnaires, and participants were categorized into two groups: active and inactive. The evaluation of the mean lung function, modified Medical Research Council dyspnea grade scores, and COPD assessment test scores was done based on the participant physical activity using a general linear model after adjusting for age, sex, smoking status, pack-years, height, and weight. In addition, a stratification analysis was performed based on the smoking status and COPD.

Results: Physical activity had a correlation with high forced expiratory volume in 1 second $\left(\mathrm{FEV}_{1}\right)$ among CODA cohort $(\mathrm{p}=0.03)$. While the active group exhibited significantly higher $\mathrm{FEV}_{1}$ compared to one exhibited by the inactive group among past smokers ( $\mathrm{p}=0.02$ ), no such correlation existed among current smokers. There was no significant difference observed in lung function after it was stratified by COPD.

Conclusion: This study established a positive correlation between regular physical activity in dusty areas and lung function in participants.

Keywords: Pulmonary Disease, Chronic Obstructive; Physical Activity; Lung Function Test; Smoking

Address for correspondence: Woo Jin Kim, M.D.

Department of Internal Medicine, Kangwon National University, 156

Baengnyeong-ro, Chuncheon 24289, Korea

Phone: 82-33-258-9364, Fax: 82-33-255-6567

E-mail: pulmo2@kangwon.ac.kr

Received: Jan. 21, 2019

Revised: Apr. 2, 2019

Accepted: May. 9, 2019

Published online: May. 31, 2019

(c) It is identical to the Creative Commons Attribution Non-Commercial License (http://creativecommons.org/licenses/by-nc/4.0/).

Copyright (C) 2019

The Korean Academy of Tuberculosis and Respiratory Diseases.

\section{Introduction}

World Health Organization (WHO) has reported that 65 million people have a moderate-to-severe chronic obstructive pulmonary disease (COPD) and that COPD will become the third leading cause of death worldwide by $2030^{1}$. COPD is reportedly characterized by both low lung function and accelerated decline in lung function ${ }^{2}$. With aging, lung function and respiratory muscle strength decrease ${ }^{3}$, and most patients with COPD are not diagnosed accurately ${ }^{4}$. Although smoking is a well-known risk factor ${ }^{5}$, environmental factors, such as air pollution and occupational exposure, are also crucial risk factors for $\mathrm{COPD}^{6}$. Furthermore, exposure to cement dust is 
correlated with a higher prevalence of COPD and respiratory symptoms ${ }^{7}$.

WHO recommends exercise training programs for managing $\mathrm{COPD}^{8}$. Physical activity reduces all-cause cardiovascular and respiratory mortality risk and exacerbation ${ }^{9,10}$. In addition, physical activity has been associated with high lung function in European study ${ }^{11}$. The beneficial effects of physical activity have been reported not only in patients with COPD but also in healthy adults and children ${ }^{12,13}$. Considering environmental pollution and lung health, it is unclear whether exposure to air pollution during physical activity affects the beneficial effects of physical activity. A previous study has reported that air pol- lution did not affect the beneficial effects of physical activity on reducing the risk of $\mathrm{COPD}^{14}$. Furthermore, physical activity positively affected lung function when performed in a highly polluted environment ${ }^{15}$. Studies on physical activity and lung function during air pollution exposure have been reported; however, studies on specific environmental exposures, such as cement dust, are limited.

The COPD in dusty areas (CODA) cohort study collected epidemiological and clinical data from participants living near cement plants where cement dust affected them ${ }^{16}$. This study aimed to assess the correlation between physical activity and lung function using the CODA study data to assess the effect

Table 1. Subjects characteristics at the baseline

\begin{tabular}{|c|c|c|c|c|}
\hline Characteristic & Total $(n=499)$ & Inactivity $(\mathrm{n}=385)$ & Activity (n=114) & p-value \\
\hline \multicolumn{5}{|l|}{ General factor } \\
\hline Age, yr & $72.3 \pm 7.3$ & $72.6 \pm 7.1$ & $71.0 \pm 7.5$ & 0.04 \\
\hline$<60$ & $28(5.6)$ & $19(4.9)$ & $9(7.9)$ & 0.34 \\
\hline $60-69$ & $115(23.1)$ & $84(21.8)$ & $31(27.2)$ & \\
\hline $70-79$ & $292(58.5)$ & $231(60.0)$ & $61(53.5)$ & \\
\hline$\geq 80$ & $64(12.8)$ & $51(13.3)$ & $13(11.4)$ & \\
\hline \multicolumn{5}{|l|}{ Sex } \\
\hline Male & $359(71.9)$ & $262(68.1)$ & $97(85.1)$ & $<0.001$ \\
\hline Female & $140(28.1)$ & $123(32.0)$ & $17(14.9)$ & \\
\hline \multicolumn{5}{|l|}{ Marriage status } \\
\hline Single & $110(22.5)$ & 89 (23.7) & $21(18.6)$ & 0.25 \\
\hline Couple & $379(77.5)$ & $287(76.3)$ & $92(81.4)$ & \\
\hline \multicolumn{5}{|l|}{ Income, won } \\
\hline$<500,000$ & $309(64.4)$ & $244(66.3)$ & $65(58.0)$ & 0.27 \\
\hline $500,000-1,000,000$ & $78(16.3)$ & $57(15.5)$ & $21(18.8)$ & \\
\hline$\geq 1,000,000$ & $93(19.4)$ & $67(18.2)$ & $26(23.2)$ & \\
\hline \multicolumn{5}{|l|}{ Life style factor } \\
\hline \multicolumn{5}{|l|}{ Smoking status } \\
\hline Never & $185(37.1)$ & $148(38.4)$ & $37(32.5)$ & 0.35 \\
\hline Former & $212(42.5)$ & $157(40.8)$ & $55(48.3)$ & \\
\hline Current & $102(20.4)$ & $80(20.8)$ & $22(19.3)$ & \\
\hline Pack-years & $17.4 \pm 23.3$ & $18.6 \pm 24.8$ & $13.6 \pm 16.8$ & 0.01 \\
\hline \multicolumn{5}{|l|}{ Anthropometric factor } \\
\hline Height, cm & $159.1 \pm 9.3$ & $158 \pm 9.4$ & $162 \pm 8.5$ & $<0.001$ \\
\hline Weight, kg & $59.6 \pm 10.4$ & $58.6 \pm 10.5$ & $62.8 \pm 9.4$ & $<0.001$ \\
\hline Body mass index, $\mathrm{kg} / \mathrm{m}^{2}$ & $23.5 \pm 3.2$ & $23.4 \pm 3.3$ & $23.9 \pm 3.0$ & 0.12 \\
\hline \multicolumn{5}{|l|}{ COPD } \\
\hline No & $175(35.1)$ & $125(32.5)$ & $50(43.9)$ & 0.02 \\
\hline Yes & 324 (64.9) & $260(67.5)$ & $64(56.1)$ & \\
\hline
\end{tabular}

Values are presented as mean \pm SD or number $(\%)$.

SD: standard deviation; COPD: chronic obstructive pulmonary disease. 
of physical activity on lung function a Korean cohort including normal and COPD-diagnosed participants in dusty areas.

\section{Materials and Methods}

\section{Study design and population}

Data from the CODA study were analyzed. The objectives and design of the CODA study have been detailed elsewhere ${ }^{17}$. Briefly, the CODA study enrolled participants living in six areas near cement plants in the Kangwon and Chungbuk provinces of South Korea. Overall, 504 participants (362 males and 142 females) were enrolled between 2012 and 2017 for baseline examinations.

At baseline examinations, data on the medical interview, survey questionnaire, spirometry, physical examination, blood/urine samples, and computed tomography were obtained from all participants. Questionnaire data included demographic factors, lifestyle factors, history of the disease, history of exacerbation, and symptoms of participants during the past year. Among the 504 participants, five with no information on physical activity were excluded from the analysis. Finally, we analyzed 499 participants. Written informed consent was given by each participants. This study received ethical approval from the Kangwon National University Hospital IRB (KNUH 2012-06-007).

\section{Measurement}

We performed spirometry using an Easy One Kit (NDD, Zurich, Switzerland). All lung function tests were performed as recommended by the American Thoracic Society/European Respiratory Society ${ }^{18}$. We defined COPD as post-bronchodilator forced expiratory volume in 1 second/forced vital capacity $\left(\mathrm{FEV}_{1} / \mathrm{FVC}\right)$ ratio of $<0.7$. We assessed physical activity using questionnaires. Participants reported whether they performed regular physical activities until they sweated during the past year (yes/no); accordingly, we categorized the participants into activity and inactivity groups.

In this study, the following demographic and lifestyle factors were included: age, sex, education, marriage status, income, smoking status, and pack-years of cigarette smoking. Dyspnea was assessed using the modified Medical Research Council (mMRC) dyspnea grade. We evaluated health-related quality of life by calculating the total score on the patient-reported COPD Assessment Test (CAT).

\section{Statistical analysis}

Continuous variables were presented as mean \pm standard deviation, and categorical variables were presented as frequencies and percentages. The least square means of the lung function, mMRC scores, and CAT scores based on physical activity were evaluated using a general linear model. The mean of lung function was adjusted for age, sex, smoking status, pack-years of cigarette smoking, and height, whereas the means of the MMRC and CAT scores were adjusted for age, sex, smoking status, and pack-years of cigarette smoking. Furthermore, we performed a stratification analysis for smoking status, COPD, and COPD severity. For classification of COPD severity among COPD patients, we classified as follows: mild, $\mathrm{FEV}_{1} \geq 80 \%$ predicted; moderate, $50 \% \leq \mathrm{FEV}_{1}<80 \%$ predicted; and $\geq$ severe, $\mathrm{FEV}_{1}<50 \%$ predicted ${ }^{19}$.

In this study, all statistical analyses were performed using SAS (version 9.4, SAS Institute Inc., Cary, NC, USA). We considered statistical significance at $\mathrm{p}<0.05$.

\section{Results}

Table 1 summarizes the baseline characteristics of the participants. The mean age of the participants was 72 years, and $72 \%$ were male. While $43 \%$ were former smokers, $20 \%$ were current smokers. In addition, the mean pack-year of cigarette smoking of the participants was 17, and the pack-years of cigarette smoking was higher in the inactivity group than the activity group.

Table 2 presents the correlation between lung function and symptoms based on physical activity at baseline. Compared with inactivity group, the mean $\mathrm{FEV}_{1}$ adjusted for confounding factors was higher in the activity group. The mean $\mathrm{FEV}_{1}$ was 1.97 and $2.09 \mathrm{~L}$ among inactive and active participants, respectively ( $\mathrm{p}=0.03$ ). However, no significant difference in the FVC, CAT scores, and mMRC scores was observed. In the stratification analysis by smoking status, the activity group exhibited higher $\mathrm{FEV}_{1}$ than that exhibited by the inactivity group among former smokers. The mean $\mathrm{FEV}_{1}$ of inactive and active participants was 1.97 and $2.18 \mathrm{~L}$, respectively $(\mathrm{p}=0.02)$. The activity group exhibited lower FVC than that exhibited by the inactivity group among current smokers. The mean FVC of inactive and active participants was 3.27 and $2.94 \mathrm{~L}$, respectively $(\mathrm{p}=0.02)$ (Table 3). We observed no significant difference in the stratification analysis by COPD (Table 4). As a result of stratification analysis by COPD severity, the activity group exhibited a higher $\mathrm{FEV}_{1}$ than the inactivity group in mild COPD subgroup (Table 5).

\section{Discussion}

This study established a correlation between physical activity and $\mathrm{FEV}_{1}$ in elderly participants from the CODA cohort study. After adjusting for confounding factors, the activity group exhibited higher $\mathrm{FEV}_{1}$ than that exhibited by the inactivity group. This correlation was observed among former 


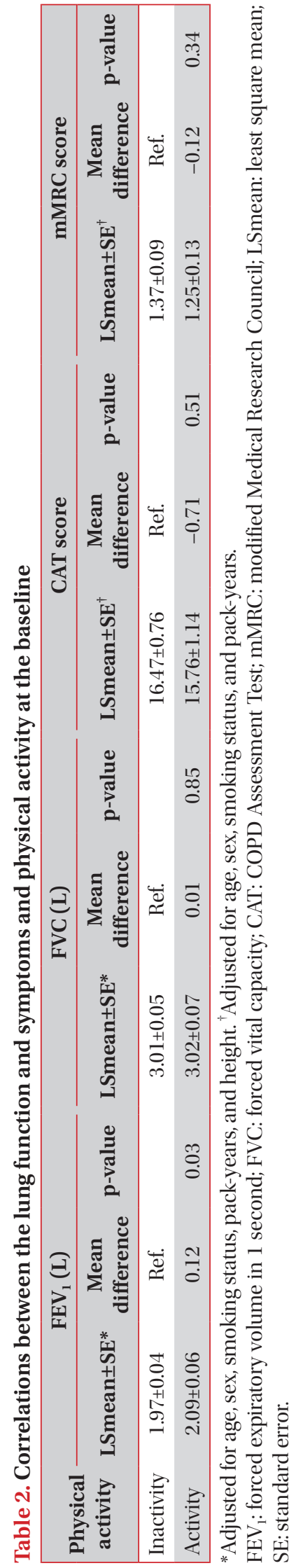

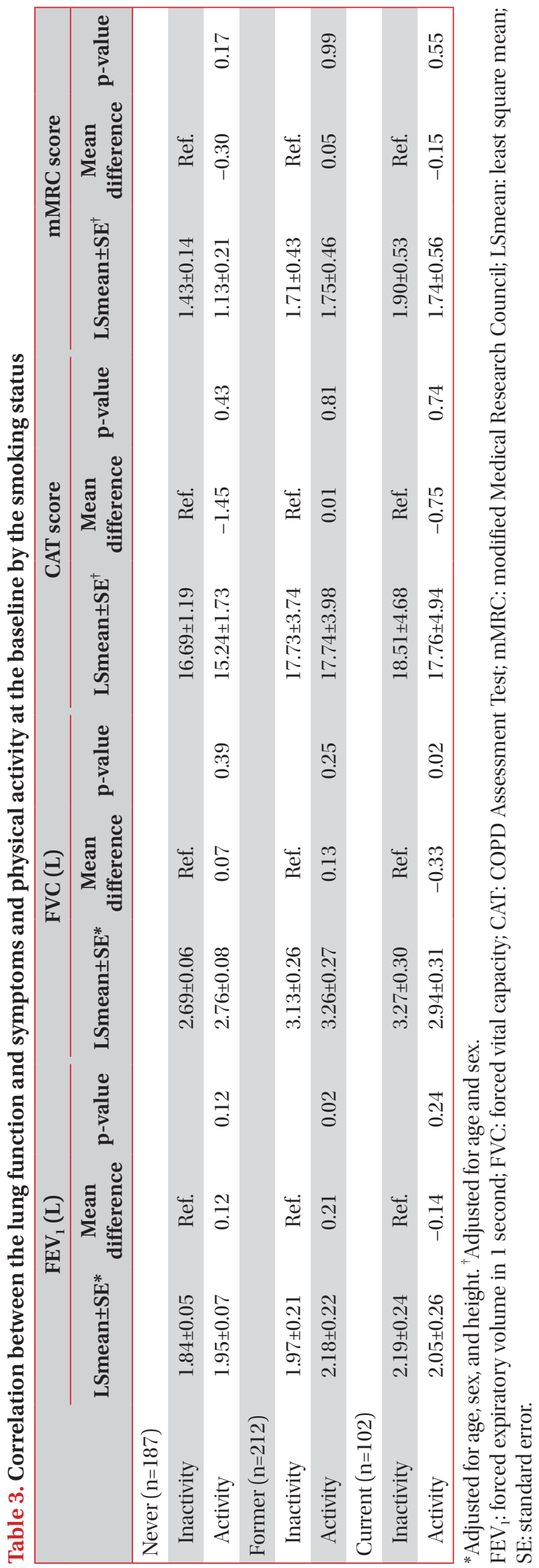



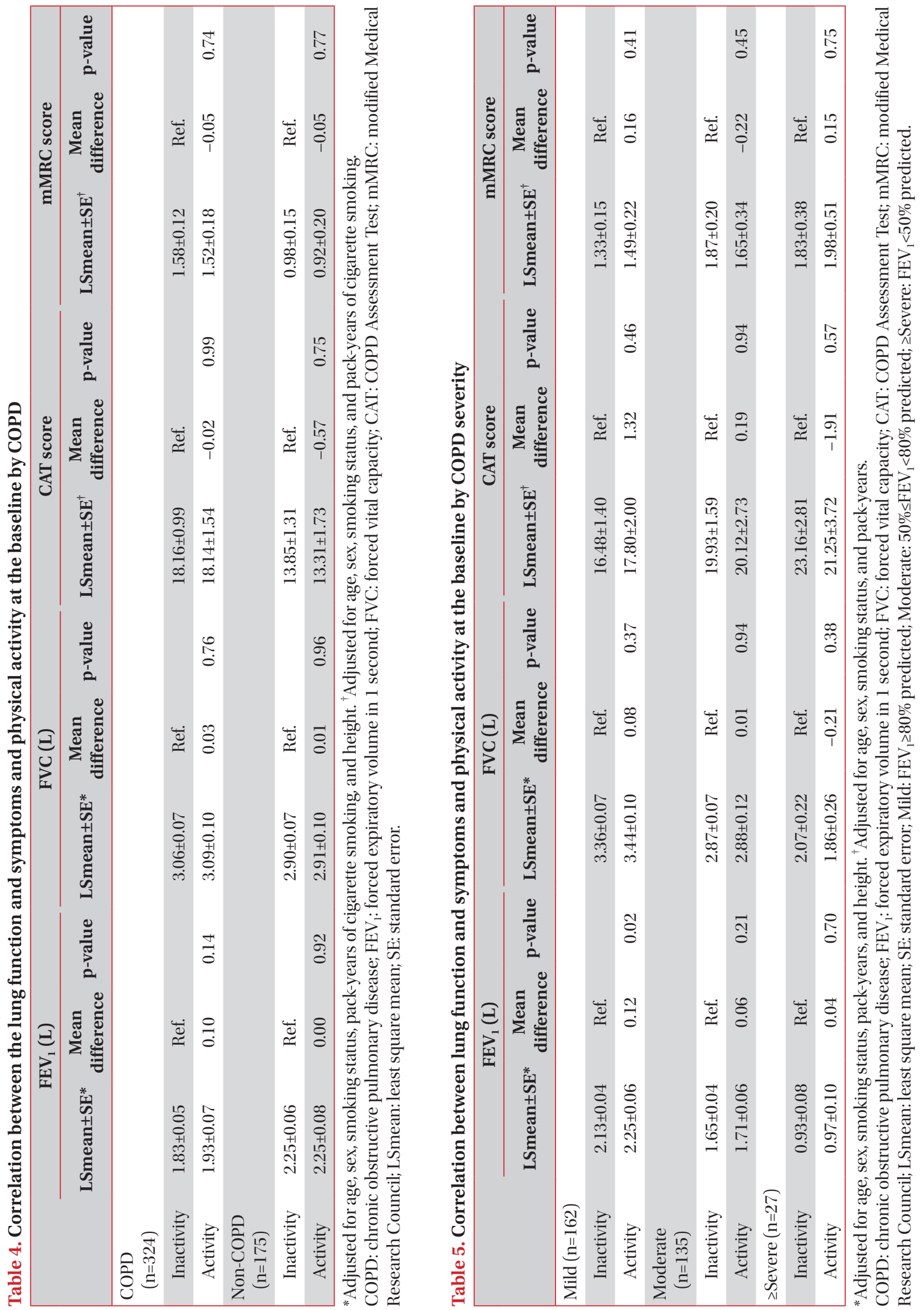
smokers; however, no such correlation was observed in the stratification analysis by COPD.

Among all the participants, only 23\% performed regular physical activity. In Korea, cement plants are located in the rural areas of Kangwon and Chungbuk that have a relatively more aged population. The Korea National Health and Nutrition Examination Survey reported that the percentage of aerobic and muscular physical activity in adults aged $>65$ years was $34.4 \%$ and $15.2 \%$, respectively ${ }^{20}$. In this study, the questionnaire focused on regular physical activities until participants sweated. Only a small proportion in this cohort answered this question affirmatively, perhaps because our study cohort represented a more aged population.

This study corroborates the findings of two prior studies on older adults. In the European Prospective Investigation of Cancer (EPIC)-Norfolk study, $\mathrm{FEV}_{1}$ was higher with escalating vigorous activity time in adults aged $45-74$ years $^{21}$. The English Longitudinal Study of Aging reported a positive correlation between physical activity and lung function in adults with an average age of 63 years $^{22}$. In COPD, which is characterized by low lung function, the quality of life could be decreased because of exacerbation, hospitalization, and mortality ${ }^{23}$, which can be reduced due to physical activity ${ }^{24,25}$. In addition, Esteban et al. have reported that among older patients with COPD, those with high levels of physical activity had enhanced health-related quality of life ${ }^{26}$. Despite being insignificant in the COPD subgroup, the current study demonstrated a positive effect of physical activity on lung function in all cohort participants. Of note, a negative result of the subgroup could be attributed to the relatively small sample size. In previous study from elderly COPD patients in Korea, increased dyspnea scale and presence of depression were associated with low-level physical activity ${ }^{27}$.

Reportedly, smoking reduces lung function and cardiorespiratory fitness ${ }^{28,29}$. Walters et al. ${ }^{30}$ have suggested that smoking accelerates the aging of small airway epithelium at molecular levels. Hence, the stratification analysis by smoking status in this study revealed that regular physical activity correlated with high $\mathrm{FEV}_{1}$ in former smokers. Prior studies have reported inconsistent results regarding the correlation between physical activity and lung function according to smoking status. Luzak et al ${ }^{13}$ have established a positive correlation between physical activity and lung function among ex-/current smokers, whereas Barboza et al. ${ }^{31}$ have reported no such correlation in smokers. In smokers, low-grade systemic inflammatory responses, including C-reactive protein, fibrinogen, interleukin-6, and white blood cells, have been identified, and most have recovered after smoking cessation. Nevertheless, several systemic inflammation markers increased in former smokers after they stopped smoking ${ }^{32}$. A study of adults aged $>40$ years indicated interactions of smoking and $\mathrm{FEV}_{1}$ on markers of systemic inflammation ${ }^{33}$. In several studies, the mechanism between physical activity and inflammatory biomarkers remains unclear, although it has been reported that physical activity correlates with low inflammatory biomarkers in elderly adults ${ }^{34-36}$. The present study has reported the positive association between lung function and physical activity in former smokers. In current smokers, these beneficial effects were not observed probably because the smoking effects were very strong. The activity group had higher $\mathrm{FEV}_{1}$ than inactivity group among mild COPD subgroup. There remain inconsistent reports in beneficial effects of physical activity on quality of life, dyspnea, or long-term disease progression in patients with mild or moderate stage ${ }^{37}$.

Our study participants lived near cement plants and were exposed to cement dust. To the best of our knowledge, very few cohort studies have investigated such specific environments. Thus, a strength of this study is the acquisition of valuable and useful data. However, this study had some limitations. First, physical activity may have been underestimated because it was assessed using questionnaires. Therefore, future studies with precise assessment of physical activity are warranted. Second, this study fails to explain the causal relationship between physical activity and lung function owing to its cross-sectional study design, necessitating future analyses with longitudinal changes in lung function.

In conclusion, this study reveals that regular physical activity correlates with $\mathrm{FEV}_{1}$ in the CODA cohort, and this correlation is most robust in former smokers. Future study will be needed to evaluate the effect of regular activity on lung function in dusty areas.

\section{Authors' Contributions}

Conceptualization: Han Y, Kim WJ. Methodology: Kwon SO, Kim WJ. Formal Analysis: Han Y. Data curation: Heo Y, Hong Y. Writing - original draft preparation: Han Y. Writing - review and editing: Heo Y, Hong Y, Kwon SO, Kim WJ. Approval of final manuscript: all authors.

\section{Conflicts of Interest}

No potential conflict of interest relevant to this article was reported.

\section{Acknowledgments}

We thank Seul-Kee Kim for technical support.

\section{Funding}

This study was supported by 2017 Research Grant from 
Kangwon National University (No. 520170447) and Ministry of Environment.

\section{References}

1. World Health Organization. Chronic respiratory diseases: burden of COPD [Internet]. Geneva: World Health Organization; 2018 [cited 2018 Nov 30]. Available from: http://www. who.int/respiratory/copd/burden/en/.

2. Celli BR, MacNee W; ATS/ERS Task Force. Standards for the diagnosis and treatment of patients with COPD: a summary of the ATS/ERS position paper. Eur Respir J 2004;23:932-46.

3. Sharma G, Goodwin J. Effect of aging on respiratory system physiology and immunology. Clin Interv Aging 2006;1:25360.

4. Hwang YI, Park YB, Yoo KH. Recent trends in the prevalence of chronic obstructive pulmonary disease in Korea. Tuberc Respir Dis 2017;80:226-9.

5. Anthonisen NR, Connett JE, Murray RP. Smoking and lung function of Lung Health Study participants after 11 years. Am J Respir Crit Care Med 2002;166:675-9.

6. Kim WJ, Lee CY. Environmental exposures and chronic obstructive pulmonary disease. Mol Cell Toxicol 2017;13:251-5.

7. Mbelambela EP, Eitoku M, Muchanga SM, Villanueva AF, Hirota R, Pulphus TY, et al. Prevalence of chronic obstructive pulmonary disease (COPD) among Congolese cement workers exposed to cement dust, in Kongo Central Province. Environ Sci Pollut Res Int 2018;25:35074-83.

8. World Health Organization. Chronic respiratory diseases: COPD management [Internet]. Geneva: World Health Organization; 2018 [cited 2018 Nov 30]. Available from: https:// www.who.int/respiratory/copd/management/en/.

9. Cheng SW, McKeough Z, Alison J, Dennis S, Hamer M, Stamatakis E. Associations of total and type-specific physical activity with mortality in chronic obstructive pulmonary disease: a population-based cohort study. BMC Public Health 2018;18:268.

10. Crook S, Busching G, Keusch S, Wieser S, Turk A, Frey M, et al. The association between daily exacerbation symptoms and physical activity in patients with chronic obstructive pulmonary disease. Int J Chron Obstruct Pulmon Dis 2018;13:2199206.

11. Fuertes E, Carsin AE, Anto JM, Bono R, Corsico AG, Demoly $\mathrm{P}$, et al. Leisure-time vigorous physical activity is associated with better lung function: the prospective ECRHS study. Tho$\operatorname{rax} 2018 ; 73: 376-84$.

12. Ji J, Wang SQ, Liu YJ, He QQ. Physical activity and lung function growth in a cohort of Chinese school children: a prospective study. PLoS One 2013;8:e66098.

13. Luzak A, Karrasch S, Thorand B, Nowak D, Holle R, Peters A, et al. Association of physical activity with lung function in lung-healthy German adults: results from the KORA FF4 study. BMC Pulm Med 2017;17:215.

14. Fisher JE, Loft S, Ulrik CS, Raaschou-Nielsen O, Hertel O, Tjonneland A, et al. Physical activity, air pollution, and the risk of asthma and chronic obstructive pulmonary disease. Am J Respir Crit Care Med 2016;194:855-65.

15. Kubesch NJ, de Nazelle A, Westerdahl D, Martinez D, Carrasco-Turigas G, Bouso L, et al. Respiratory and inflammatory responses to short-term exposure to traffic-related air pollution with and without moderate physical activity. Occup Environ Med 2015;72:284-93.

16. Hong Y, Kwon JW, Lee SA, Han YJ, Moon JY, Kim HY, et al. Methodology of an observational cohort study for subjects with chronic obstructive pulmonary disease in dusty areas near cement plants. J Pulm Respir Med 2014;4:169.

17. Kim S, Lim MN, Hong Y, Han SS, Lee SJ, Kim WJ. A cluster analysis of chronic obstructive pulmonary disease in dusty areas cohort identified three subgroups. BMC Pulm Med 2017;17:209.

18. Miller MR, Hankinson J, Brusasco V, Burgos F, Casaburi R, Coates A, et al. Standardisation of spirometry. Eur Respir J 2005;26:319-38.

19. Rabe KF, Hurd S, Anzueto A, Barnes PJ, Buist SA, Calverley P, et al. Global strategy for the diagnosis, management, and prevention of chronic obstructive pulmonary disease: GOLD executive summary. Am J Respir Crit Care Med 2007;176:53255.

20. Korea Centers for Disease Control and Prevention. Korea Health Statistics 2016: Korea National Health and Nutrition Examination Survey (KNHANES VII-1) [Internet]. Cheongju: Korea Centers for Disease Control and Prevention; 2016 [cited 2018 Jan 10]. Available from: https://knhanes.cdc.go.kr/ knhanes/sub04/sub04_03.do?classType=7.

21. Jakes RW, Day NE, Patel B, Khaw KT, Oakes S, Luben R, et al. Physical inactivity is associated with lower forced expiratory volume in 1 second: European Prospective Investigation into Cancer-Norfolk Prospective Population Study. Am J Epidemiol 2002;156:139-47.

22. O'Donovan G, Hamer M. The association between leisuretime physical activity and lung function in older adults: The English longitudinal study of ageing. Prev Med 2018;106:1459 .

23. Esteban C, Quintana JM, Moraza J, Aburto M, Egurrola M, Espana PP, et al. Impact of hospitalisations for exacerbations of COPD on health-related quality of life. Respir Med 2009;103:1201-8.

24. Schonmann M, Sievi NA, Clarenbach CF, Brack T, Brutsche M, Frey M, et al. Physical activity and the frequency of acute exacerbations in patients with chronic obstructive pulmonary disease. Lung 2015;193:63-70.

25. Garcia-Aymerich J, Lange P, Benet M, Schnohr P, Anto JM. Regular physical activity reduces hospital admission and mortality in chronic obstructive pulmonary disease: a population based cohort study. Thorax 2006;61:772-8. 
26. Esteban C, Quintana JM, Aburto M, Moraza J, Egurrola M, Perez-Izquierdo J, et al. Impact of changes in physical activity on health-related quality of life among patients with COPD. Eur Respir J 2010;36:292-300.

27. Lee SH, Kim KU, Lee H, Kim YS, Lee MK, Park HK. Factors associated with low-level physical activity in elderly patients with chronic obstructive pulmonary disease. Korean J Intern Med 2018;33:130-7.

28. Higgins MW, Enright PL, Kronmal RA, Schenker MB, AntonCulver H, Lyles M. Smoking and lung function in elderly men and women. The Cardiovascular Health Study. JAMA 1993;269:2741-8.

29. de Borba AT, Jost RT, Gass R, Nedel FB, Cardoso DM, Pohl $\mathrm{HH}$, et al. The influence of active and passive smoking on the cardiorespiratory fitness of adults. Multidiscip Respir Med 2014;9:34.

30. Walters MS, De BP, Salit J, Buro-Auriemma LJ, Wilson T, Rogalski AM, et al. Smoking accelerates aging of the small airway epithelium. Respir Res 2014;15:94.

31. Barboza ML, Barbosa AC, Spina GD, Sperandio EF, Arantes RL, Gagliardi AR, et al. Association between physical activity in daily life and pulmonary function in adult smokers. J Bras Pneumol 2016;42:130-5.

32. Yanbaeva DG, Dentener MA, Creutzberg EC, Wesseling G,
Wouters EF. Systemic effects of smoking. Chest 2007;131: 1557-66.

33. Gan WQ, Man SF, Sin DD. The interactions between cigarette smoking and reduced lung function on systemic inflammation. Chest 2005;127:558-64.

34. Elosua R, Bartali B, Ordovas JM, Corsi AM, Lauretani F, Ferrucci L, et al. Association between physical activity, physical performance, and inflammatory biomarkers in an elderly population: the InCHIANTI study. J Gerontol A Biol Sci Med Sci 2005;60:760-7.

35. Colbert LH, Visser M, Simonsick EM, Tracy RP, Newman AB, Kritchevsky SB, et al. Physical activity, exercise, and inflammatory markers in older adults: findings from the Health, Aging and Body Composition Study. J Am Geriatr Soc 2004;52: 1098-104.

36. Reuben DB, Judd-Hamilton L, Harris TB, Seeman TE; MacArthur Studies of Successful Aging. The associations between physical activity and inflammatory markers in high-functioning older persons: MacArthur Studies of Successful Aging. J Am Geriatr Soc 2003;51:1125-30.

37. Chavannes N, Vollenberg JJ, van Schayck CP, Wouters EF. Effects of physical activity in mild to moderate COPD: a systematic review. Br J Gen Pract 2002;52:574-8. 